\title{
Ensino-aprendizagem de Língua Espanhola no Projeto Casas de Cultura no Campus da Universidade Federal de Alagoas: propostas e encaminhamentos para formação crítica
}

\author{
Gustavo Correia dos Santos ${ }^{1}$ \\ Flávia Colen Meniconi ${ }^{1}$
}

\section{Resumo}

Este artigo é resultado de uma pesquisa sobre o processo de formação crítica e de escrita argumentativa em Lingua Espanhola. Baseamo-nos nas contribuições de Barton; Hamilton (2000) e Gee (2000) que defendem a valorização do sujeito; Rojo (2004), que discute sobre o contexto social no processo de aprendizagem, Perelman; Olbrechts-Tyteca (2005), que discorrem sobre aspectos argumentativos da lingua e Meniconi (2017) que, por sua ver, defende o ensino da escrita em Lingua Espanhola nas fases iniciais de sua aprendizagem. Esta é uma pesquisa de caráter qualitativo e teve como objetivo analisar o processo de ensino-aprendizagem da escrita argumentativa em espanhol. Os resultados revelaram que, a partir do trabalho realizado, os alunos foram capazes de produzir textos argumentativos no idioma estudado. A sequência didática desenvolvida possibiliton desenvolver a criticidade nos textos produحidos, bem como o uso de estratégias argumentativas para defender o ponto de vista e os valores em língua espanhola.

Palavras-chave: Letramento Crítico. Escrita Argumentativa. Ensino-aprendiragem de Lingua Espanbola

${ }^{1}$ Universidade Federal de Alagoas. 


\section{Introdução e objetivos}

Sabe-se que a produção textual é uma habilidade extremamente complexa. A escrita coesa e coerente requer o conhecimento não só de elementos léxicos e gramaticais do idioma, mas também da articulação clara e organizada das ideias e argumentos em um texto. Entretanto, o que se observa é que a produção textual, na perspectiva processual, raramente é trabalhada no ensino de idiomas. Ainda hoje, há um predomínio do ensino frasal, gramatical e descontextualizado da língua estrangeira. Nas palavras de Meniconi (2017), "essa fixação nos elementos gramaticais pode ser devido ao fato de que muitos professores não têm embasamento teórico para perceber e trabalhar com outros elementos textuais, além das regras estruturais do idioma” (MENICONI, 2017, p. 19).

Com o intuito de contribuir para o desenvolvimento da escrita a partir de uma proposta mais discursiva, esta pesquisa trabalhou com o ensino da escrita argumentativa em língua espanhola com alunos participantes de um projeto de extensão do curso de Letras/Espanhol da Universidade Federal de Alagoas. O trabalho foi realizado no período no período de janeiro a julho de 2016 em uma turma de língua espanhola do nível Intermediário I.

O projeto de extensão referido, conhecido como "Casas de Cultura no Campus" (CCC), oferece cursos gratuitos de línguas estrangeiras para alunos da Ufal e de escolas públicas parceiras da universidade. Os acadêmicos do curso de Letras/Espanhol participantes do projeto, denominados PFIs (professores em formação inicial), ensinam o idioma espanhol, por meio da articulação entre o conhecimento linguístico e a formação crítica, cidadã e transformadora. De acordo com Baran e Sweezy, citados por Mészáros (2002),

Desde a mais tenra infância, as pessoas aprendem por todos os meios concebíveis que todos têm oportunidades iguais e que as desigualdades com que se deparam não são o resultado de instituições injustas, mas de seus dotes naturais superiores ou inferiores (BARAN; SWEEZY apud MÉSZÁROS, 2002, p. 273-274).

Desde que somos crianças nos é passada a ideia de que cada um de nós é responsável pelos sucessos e insucessos na vida e de que todos somos iguais perante a lei. Essa informação pode ser comprovada no artigo primeiro da Declaração dos Direitos do Homem e do Cidadão, de 1789, que ressalta a igualdade. No entanto, nem todos possuem a mesma trajetória. Nesse contexto, as diferenças de experiências e de histórias de vida 
destacam a importância da defesa da equidade social, principalmente no âmbito educacional. Isso porque o acesso à educação repercute de maneira positiva na eliminação das barreiras sociais, econômicas e culturais da sociedade em geral. Nesse contexto, acreditamos que podemos contribuir para a diminuição desses entraves a partir de um trabalho voltado para a formação crítica. Em outras palavras, defendemos o ensinoaprendizagem do idioma espanhol dentro de uma dimensão mais crítica e discursiva, intermediado por práticas letradas, o que vai de encontro com a perspectiva de ensino estritamente gramatical. Essa concepção norteou as leituras, discussões e atividades práticas realizadas com os participantes dessa investigação.

Nosso objetivo, nessa pesquisa, foi discutir sobre os resultados de uma investigação realizada com duas turmas de nível intermediário de língua espanhola. Inicialmente, analisamos as nossas ações de planejar, ministrar e refletir sobre as atividades de produção escrita dos alunos, com foco em textos argumentativos e as implicações desse trabalho na formação crítica. Assim, objetivamos responder duas perguntas: (1) Quais características são identificadas entre o planejamento de aulas e as aulas ministradas pelo professor/pesquisador com foco na produção escrita? (2) O que as produções escritas revelam sobre o processo de produção textual trabalhado em língua espanhola?

Como fundamentação teórica, embasamo-nos nas contribuições de Barton e Hamilton (2000) e Gee (2000), que ressaltam a importância de se valorizar a subjetividade do aluno, assim como o contexto social (ROJO, 2004). Apoiamo-nos em Perelman e Olbrechts-Tyteca (2005), que relatam a necessidade de trazer para a sala de aula o trabalho com os aspectos argumentativos da língua. Sobre essa questão, é importante salientar que entendemos a língua como discurso (JORDÃO; FOGAÇA, 2007). Ainda sobre esse aspecto, Meniconi (2015) chama a atenção para a valorização do processo de escrita como um todo, conforme podemos perceber em suas palavras: "é preciso ir além da análise do produto textual, isto é, o texto pronto, e passar a compreender e a trabalhar com a escrita dentro de uma perspectiva processual” (MENICONI, 2015, p. 38).

Para alcançar os objetivos propostos nessa pesquisa, alguns instrumentos de coleta foram utilizados: questionário inicial, planos de aula, atividades de produção escrita, diários reflexivos do professor, comentários dos alunos sobre as atividades e entrevistas com os alunos. Assim, o presente trabalho objetivou investigar as ações do Professor em Formação Inicial - PFI - no processo de planejar, ministrar e refletir sobre as atividades de produção 
escrita com foco em textos argumentativos e os reflexos do trabalho de formação crítica expresso nas produções escritas. Nesse sentido, procuramos:

1- Identificar as características entre o planejamento e execução das aulas ministradas com foco na produção escrita e no letramento crítico;

2- Verificar o que as produções escritas revelam sobre o trabalho com o processo de escrita em língua espanhola;

3- Proporcionar uma formação crítica objetivando não apenas o ensino-aprendizagem dos aspectos gramaticais e léxicos da língua espanhola, mas também incentivar a reflexão acerca das crenças e valores inerentes a cada um dos sujeitos envolvidos nesta investigação.

4- Facilitar a escrita em língua espanhola por meio da percepção desta como um processo.

No tópico a seguir, nos dedicaremos a tratar sobre a complexidade da escrita em língua estrangeira, neste caso, a língua espanhola.

\section{A complexidade da escrita em Língua Espanhola}

Desde Aristóteles c. 330 AC/1932L, o processo de escrita é considerado como uma série de decisões e escolhas. No entanto, Flower e Hayes (1981) afirmam que já não é tão fácil sustentar esta ideia sem que estejamos preparados para responder ao seguinte questionamento: o que orienta a decisão de um escritor sobre o que escrever?

Flower e Hayes (1981) explicitam estas estratégias utilizadas no processo de escrita:

1. A ação de redigir é o conjunto de processos distintivos do pensamento organizados ou orquestrados pelo escritor durante o ato da composição.

2. Estes processos têm uma organização hierárquica com uma alta capacidade de inserção na qual um processo em particular pode ser inserido dentro de qualquer outro.

3. $\mathrm{O}$ ato de compor é em si mesmo um processo do pensamento orientado com um objetivo, conduzido por uma rede de objetivos cada vez maiores e próprios do escritor.

4. Os escritores criam seus próprios fins de duas maneiras: propondo objetivos de alto nível e respaldando objetivos subordinados 
que dão vida ao sentido do propósito que vai se desenvolvendo no escritor (FLOWER; HAYES, 1981, p. 3. Tradução nossa²).

Sobre o primeiro ponto, os autores afirmam que a pré-escrita é a fase anterior à aparição das palavras sobre o papel. Já na escrita, o autor redige o produto e, na reescrita, trabalha o produto de maneira definitiva. No entanto, Flower e Hayes (1981) afirmam que os autores estão sempre planejando (pré-escrevendo), revisando (reescrevendo), na medida em que compõem (escrevem) e que estas etapas não são totalmente inidentificáveis. Já sobre o texto escrito, as autoras asseveram que, durante o processo de escrita, novas ideias surgem e estas precisam estar organizadas em parágrafos. Elas ainda afirmam que um dos maiores desafios do escritor é dar continuidade às orações previas, no sentido de escolher como continuar o processo. Para Meniconi (2017), o escritor

precisa imaginar o texto na perspectiva do leitor, formular objetivos em relação ao que pretende atingir com o seu discurso, estabelecer planos procedimentais para o seu texto, gerar, organizar ideias e revisá-lo. [...] A didática de ensino da escrita deve levar em conta não só a adequação das regras gramaticais, mas também os problemas retóricos. Para tanto, é preciso ir além da análise do produto textual, isto é, o texto pronto, e passar a compreender e a trabalhar com a escrita dentro de uma perspectiva processual (MENICONI, 2017, p. 39).

Assim, portanto, no ato de escrita, é necessário que, inicialmente, o aluno passe pelo planejamento, pelos processos de escrita, reescrita e que imagine para quem escreve determinado texto, isto é, que se coloque no lugar do leitor. Vale destacar que não devemos considerar apenas as adequações gramaticais. É também necessário compreender o processo de escrita. Considerar esse processo implica em valorizar a marca deixada por cada um ao escrever seus textos, visto que, por meio da escrita expressamos nossas crenças, valores e experiências pessoais. Este tema será aprofundado a partir das teorias relacionadas à escrita argumentativa e ao letramento crítico no ensino da escrita, discutidas no tópico a seguir.

\footnotetext{
2 Texto original em inglês: " 1 . The process of writing is best understood as a set of distinctive thinking processes which writers orchestrate or organize during the act of composing.

2. These processes have a hierarchical, highly embedded organization in which any given process can be embedded within any other.

3. The act of composing itself is a goal-directed thinking process, guided by the writer's own growing network of goals.

4. Writers create their own goals in two key ways: by generating both high-level goals and supporting subgoals which embody the writer's developing sense of purpose, and then, at times, by changing major goals or even establishing entirely new ones based on what has been earned in the act of writing" (FLOWER; HAYES, 1981, p. 3).
} 


\section{A escrita argumentativa e letramento crítico}

\section{O Letramento Crítico}

O termo letramento crítico surgiu no Brasil, na década de 80, por meio da palavra literacy, presente na publicação da obra de Mary Kato, em 1986, intitulada "No mundo da escrita: uma perspectiva psicolinguística”. Tal termo surgiu como maneira de sobrepujar-se ao conceito de alfabetização (leitura e escrita), já que um sujeito alfabetizado nem sempre pode ser considerado como um sujeito letrado. No processo de alfabetização, o aluno vai aprender apenas a ler e escrever (SANTOS; IFA, 2013). O sujeito letrado, por sua vez, saberá ler e escrever, além de reagir às práticas sociais discursivas, conforme defende Soares (1998)

É esse, pois, o sentido que tem letramento, palavras que criamos traduzindo "ao pé da letra" o inglês literacy: letra-, do latim littera, e o sufixo -mento, que denota resultado de uma ação (como, por exemplo, em ferimento, resultado da ação de ferir) (SOARES, 1998, p. 18).

No entanto, letramento crítico vai além de alfabetizar-se. Segundo Freire (1977), o ser letrado pensa, comunica, transforma e está habilitado para discutir e confrontar ideias. O letramento está relacionado com as relações de interesse e poder. Em outro âmbito de análise, Rojo (2004) reitera que

escapar da literalidade dos textos e interpretá-los, colocando-os em relação com outros textos e discursos, de maneira situada na realidade social, é discutir com os textos, replicando e avaliando posições e ideologias que constituem seus sentidos; é, enfim, trazer o texto para a vida e colocá-lo em relação com ela (ROJO, 2004, p. 2).

Rojo relata ainda sobre o ato de ler no século passado. Segundo a autora, o ato de ler era visto somente como um processo de decodificação de grafemas em fonemas. Nesta época, aprender a ler estava relacionado com alfabetização. No entanto, a decodificação não era suficiente para as possíveis capacidades cabíveis ao ato de ler. Nessa mesma linha, a autora nos revela sua concepção de letramento enquanto leitura. Para Rojo (2004),

A leitura passa, primeiro, a ser enfocada não apenas como um ato de decodificação, de transposição de um código (escrito) a outro (oral), mas como um ato de cognição, de compreensão, que envolve conhecimento de mundo, conhecimento de práticas sociais e conhecimentos linguísticos muito além dos fonemas (ROJO, 2004, p. 3). 
Dessa maneira, os conhecimentos de mundo do leitor contribuirão para que o texto seja não somente decodificado, mas também compreendido e, possivelmente, contestado. A leitura como prática social leva o leitor a apoderar-se do texto e relacioná-lo com seus valores, crenças e concepções.

Jordão e Fogaça (2007) relatam uma experiência de elaboração de materiais didáticos para escolas públicas, tendo como base o letramento crítico. Eles procuraram utilizar textos que permitissem o desenvolvimento de uma visão crítica no aluno e não somente a exploração de aspectos linguísticos.

De acordo com Jordão e Fogaça (2007)

Quando a língua é definida como discurso, o ensino de LEs se torna o ensino de novas formas de nos compreendermos e de percebermos o mundo. A língua como discurso implica o entendimento de nossas práticas de linguagem como práticas de (re)significarmos o mundo e o que acontece em nossa volta, a forma como percebemos a realidade. (JORDÃO; FOGAÇA, 2007, p. 87).

Nesse sentido, o letramento crítico concebe a língua como discurso, como construtora de novos significados, identidades e posições, visto que, por meio dela, entendemos e interpretamos as nossas experiências. Em outras palavras, o letramento crítico é uma prática educacional que concebe a língua como formadora de ideias e valores que permitem ao sujeito ser capaz de (re)significar suas próprias crenças e valores, a fim de provocar a transformação social.

\section{A escrita argumentativa}

A argumentação é uma competência básica que utilizamos na defesa de pontos de vista contrários, para tomar decisões, persuadir o outro a modificar o seu comportamento e justificar nossos comportamentos. A argumentação está presente em todos os âmbitos sociais: o político argumenta para ganhar votos, o advogado para ganhar uma causa, o cientista para defender uma hipótese, o publicitário para vender um produto.

Para Aristóteles (1998), em um discurso deve haver três elementos fundamentais: a pessoa que fala (orador), o assunto e as pessoas para quem se fala (auditório). Estes três 
elementos estão relacionados diretamente aos três tipos de argumento definidos por Aristóteles: o Lógos, o Ethos e o Páthos.

De acordo com Meyer (2007), “o logos subordina a suas regras próprias o orador e o auditório: ele persuade um auditório pela forma de seus argumentos, ou agrada a esse mesmo auditório pela beleza do estilo, que comove aqueles a quem se dirige” (MEYER, 2007, p. 22). Ainda segundo Meyer (2007), o pathos representa as emoções, paixões e perguntas do auditório. A paixão em retórica tem a ver com os sentimentos inerentes ao leitor. Já o ethos é a imagem de si mesmo, conforme assevera Meyer (2007), os gregos definiam o ethos como a imagem de si mesmo, o caráter, a personalidade, os traços de comportamento, a escolha de vida e dos fins. Por isso, a palavra ética vem de ethos. Para levar nosso interlocutor à adesão de nossa tese, é preciso que sejamos coerentes e não apresentemos contradições, é essencial que apresentemos recursos que induzam à aceitação daquela. Segundo Koch (2002),

Como ser dotado de razão e vontade, o homem, constantemente, avalia, julga, critica, isto é, forma juízos e valor. Por outro lado, por meio do discurso - ação verbal dotada de intencionalidade - tenta fluir sobre o comportamento do outro ou fazer com que compartilhe determinadas de suas opiniões. É por esta razão que se pode afirmar que o ato de argumentar constitui linguístico fundamental, pois, a todo e qualquer momento subjaz uma, na acepção mais ampla do termo (KOCH, 2002, p. 19, grifos da autora).

O ato de argumentar faz parte da natureza humana e o discurso está coberto de avaliações, julgamentos, concordâncias e discordâncias, valores e juízos. Entretanto, a escrita argumentativa não é tão simples assim, pois para ser compreendido no texto produzido, é de fundamental importância articular nossos pensamentos de forma adequada, com o objetivo de atingir o entendimento do leitor. Mas, afinal de contas, o que seria argumentar? Argumentar, de acordo com Sosa (2011):

É um jogo da linguagem do pensamento, ou seja, uma prática linguística submetida a regras. As razões que se apresentam para justificar um fato ou algo que foi dito pretendem ter validade intersubjetiva suscetível de crítica precisamente para chegar, através dela, a acordos comunicativos (SOSA, 2011, p. 177, tradução nossa33).

\footnotetext{
3 Texto original em espanhol: "Argumentar es un juego del lenguaje y del pensamiento, es decir, una práctica lingüística sometida a reglas. Las razones que se presentan para justificar un hecho o dicho pretenden tener validez intersubjetiva susceptible de crítica precisamente para llegar, a través de ella, a acuerdos comunicativos" (SOSA, 2011, p. 177).
} 
Em concordância com Sosa (2011), Habermas (1991) define a argumentação como "um meio para conseguir entendimento linguístico, entendimento que só sujeitos capazes de linguagem e de ação podem alcançar" (SOSA, 2011, p. 177, tradução nossa ${ }^{4}$ ). Sendo assim, escrita argumentativa está relacionada ao conjunto de ações humanas cujo objetivo é levar o outro a concordar com determinada ideia, por meio do convencimento ou da persuasão.

Além disso, a escrita argumentativa pode também oportunizar a reflexão sobre o contexto de produção, isto é, sobre o grupo social para o qual o texto foi produzido ou quer alcançar. Sobre esse aspecto, Rocha (2012) defende que

não basta os alunos serem expostos a uma gama considerável de textos; é fundamental levá-los a refletir sobre as coerções das esferas sociais em que esses textos circulam. $\mathrm{O}$ ensino da língua [...] na escola deve inserir as práticas sociais de leitura e escrita nas situações de produção, recepção, circulação dos textos, a fim de que esses motivem a construção dos sentidos (ROCHA, 2012, p. 203).

Dessa forma, pode-se dizer que a argumentação está fortemente ligada ao contexto, ou seja, os argumentos não surgem do vazio. A construção de sentidos em textos argumentativos ocorrerá, justamente, a partir do olhar crítico sobre o contexto de produção, nos âmbitos da produção, da leitura, da circulação, entre outros elementos. Dentro desse enfoque, nossa pesquisa buscou trabalhar a construção de sentidos na leitura e produção de textos, a partir do conhecimento de estratégias argumentativas e contextos de produção de textos propostos para leitura e produção textual.

$\mathrm{Na}$ seção seguinte descreveremos a metodologia utilizada na pesquisa que, por sua vez, é de caráter qualitativo, com base interventiva.

\section{Metodologia}

Adotamos a pesquisa de caráter qualitativo porque nos permite uma aproximação e um entendimento mais profundo e significativo acerca da realidade a ser investigada. A partir dessa metodologia, investigamos o processo ensino-aprendizagem da língua espanhola em um contexto natural e real: a sala de aula do projeto CCC (língua espanhola).

\footnotetext{
4 Texto original em espanhol: "un medio para conseguir entendimiento lingǘstico, entendimiento que solamente pueden alcanzar sujetos capaces de lenguaje y de acción” (HABERMAS, 1991).
} 
Por entender que a pesquisa-ação envolve etapas, a saber: planejamento, ações concretas em sala de aula, reflexão sobre o acontecido e possíveis conexões com a teoria lida e estudada, o método adotado para a realização dessa investigação foi a da pesquisa-ação (THIOLLENT, 1997). A pesquisa-ação está baseada na descrição e observação de situações reais e é utilizada para a resolução ou esclarecimento de um problema coletivo, no caso a produção escrita em língua espanhola, habilidade pouco explorada no processo de ensino-aprendizagem de idiomas.

A pesquisa que relatamos foi desenvolvida em dois semestres do curso de espanhol na CCC (2015.2 e 2016.1). Inicialmente, a pesquisa foi realizada com um grupo de 12 alunos, no primeiro semestre, e seis participantes durante o último semestre.

Para tanto, foram elaborados dois questionários. O primeiro continha quatro perguntas discursivas e o segundo duas perguntas de múltipla escolha. As perguntas tinham como objetivo descobrir os fatores que levaram os participantes da pesquisa a estudarem a língua alvo, suas experiências em outras turmas e os temas que eles gostariam que fossem trabalhados durante o semestre. Responderam à entrevista seis alunos, conforme pode ser observado na análise de dados.

Aluno (a): Data: / /2016

Professor: Gustavo Correia Matéria: Español - Pré-Inter 1

1. Com que finalidade você está estudando espanhol? Leia as seguintes afirmações e marque um " $\mathrm{X}$ " nas que você pensa que sejam importantes.

( ) Eu gosto da língua e da cultura dos países hispanohablantes. （ ） Preciso do espanhol no meu trabalho.

( ) Tenho que escolher uma língua estrangeira nos meus estudos. ( ) Quero ler jornais, revistas e textos em espanhol.

( ) Quero assistir filmes e programas de televisão em espanhol. （ ) Me interesso pela literatura hispano-americana.

2. ¿Qué temas, a continuación, te gustan más? Elige dos temas.
( ) Política
( ) Social
( ) Fútbol
( ) Religión
( ) Cultura
( ) Ecología
( ) Lengua y literatura

Quadro 1: questionário desenvolvido pelos pesquisadores. 
Após a aplicação dos questionários, analisamos as respostas e elaboramos os seguintes gráficos:

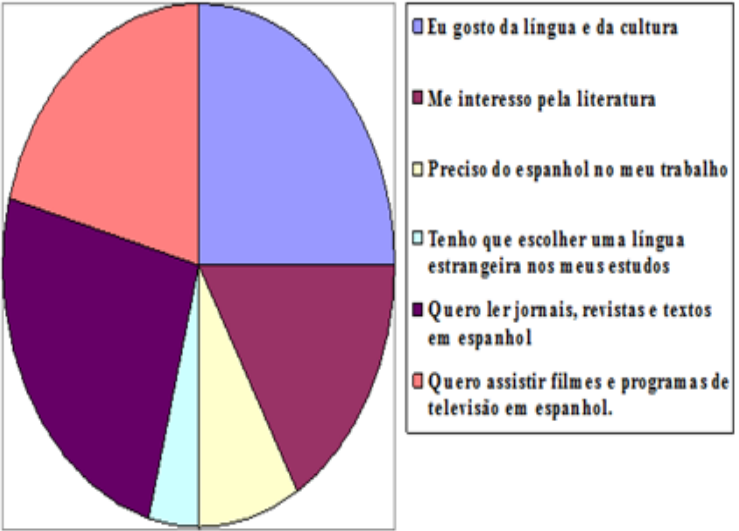

Gráfico 1

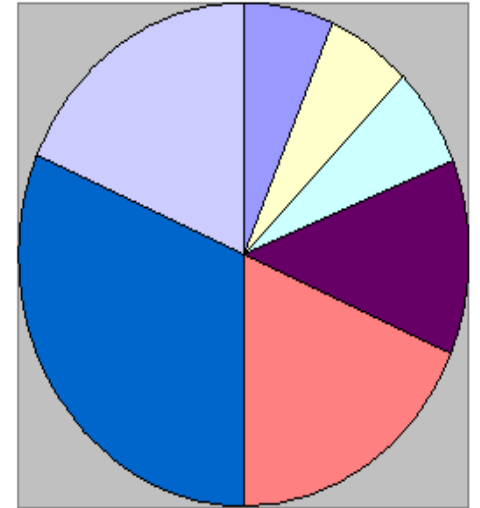

$\square$ Política

๑ Fútbol

$\square$ Religión

$\square$ Ecología

— Social

$\square$ Emocional

$\square$ Cultura

\section{Gráfico 2}

Gráfico 1: gráficos elaborados pelos pesquisadores.

As respostas refletidas nos gráficos nos serviram de base para elaborar as aulas. Tentamos, a partir da análise dessas informações, contemplar os temas e objetivos levantados pelos alunos, tais como o interesse pela cultura e pela leitura de jornais, revistas e textos em espanhol.

A primeira turma estava composta de 12 alunos, com a faixa etária compreendida entre 18 e 25 anos. A segunda turma, por sua vez, tinha seis alunas. Vale ressaltar que os participantes da pesquisa eram oriundos de cursos de graduação da Universidade Federal de Alagoas.

A primeira turma participou do projeto durante o período de agosto a novembro de 2015. Já a segunda frequentou o curso entre janeiro de maio de 2016. Durante esses períodos, trabalhamos com os nossos alunos a partir do ensino explícito de estratégias argumentativas que os permitissem expressar o ponto de vista sobre determinado tema em língua espanhola e defender suas opiniões, utilizando, para isso, técnicas retóricas, tais como: os argumentos pragmáticos, os exemplos, os modelos, os anti-modelos, as analogias, os argumentos de autoridade, entre outros (REBOUL, 1998; OLBRECHTS-TYTECA, 2005). Cabe ressaltar que todas as atividades de produção dos textos foram baseadas em um processo de planejamento das ideias, escrita, correção e reescrita (MENICONI, 2015). 
Os instrumentos utilizados para a coleta de dados foram: questionários, planos de aula, diários de aula, comentários dos alunos em redes sociais, gravação em áudio e vídeo, tarefas. Na seção a seguir, apresentamos a análise dos dados.

\section{Análise de dados}

Os resultados das respostas aos questionários referidos nos serviram de base para elaborar as aulas a partir dos temas que pareceram interessantes para os participantes da pesquisa e seus objetivos no curso, como já foi salientado anteriormente. Para tanto, utilizamos músicas, filmes, artigos de opinião e vídeos referentes aos temas escolhidos pelos alunos.

Em um primeiro momento, a análise das respostas às entrevistas revelou que o interesse da maioria dos alunos era aprender a língua espanhola para viajar, ler livros e artigos e conseguir um trabalho que exigisse o conhecimento do idioma. Três alunos ressaltaram a importância de participar do curso com o objetivo de melhorar a pronúncia e seus conhecimentos gramaticais. Todos afirmaram que gostavam de ler e alguns disseram que o curso os ajudaria a ler em língua espanhola. A grande maioria respondeu que lia livros e jornais por meio da internet pelo fato de ser mais acessível. A aluna A2 afirmou que se interessava por literatura, psicologia, turismo e que lia os temas relacionados a essas áreas em seu tempo ocioso. Seguem alguns fragmentos referentes aos discursos dos alunos sobre o tema:

Aluna A2: Eu sempre quis aprender um novo idioma, ne? Para mim é muito importante. Porque eu quero fazer intercâmbio.

Aluna A1: Eu também penso em intercâmbio... e, assim, é bom ter um segundo idioma... a gente pode ler mais coisas.

Aluna A2: Eu mesma gosto de ler sobre tudo... mas, gosto mesmo de ler em Psicologia e Literatura... e acho muita coisa em espanhol.

Além disso, todos eles asseguraram também que a experiência nos cursos de espanhol que fizeram anteriormente havia sido proveitosa. A experiência contribuiu para que aprimorassem os conhecimentos gramaticais e o vocabulário, bem como o desenvolvimento da conversação e pronúncia. 
A2: "Ao longo desses últimos semestres, houve um avanço significativo da gramática e do vocabulário, mediante a inclusão de estratégias de ensino como atividades na sala e dinâmicas".

A4: "Posso dizer que a experiência tem sido muito boa".

A maioria dos alunos sugeriu que o professor trabalhasse com leituras, atividades que envolvessem a gramática, a exibição de filmes e o uso de canções como ferramenta de aprendizagem e estudo da cultura de países hispânicos. A grande maioria sugeriu o trabalho com a conversação e a gramática. Todos os alunos foram favoráveis ao ensino por temas, argumentando que a estratégia didática poderia auxiliar no desenvolvimento da comunicação em língua espanhola. Uma aluna comentou sobre a importância de ler um texto e, em seguida, discuti-lo. Seis alunos sugeriram o uso de textos polêmicos tais como: aborto, homossexualidade, política, feminismo, religião, sob a afirmação de que as provocações que possivelmente aparecessem nos textos estimulariam a comunicação, a partir da manifestação de opiniões favoráveis ou desfavoráveis ao tema.

A3: É bom aqueles temas que ninguém quer falar...

A1: Como assim, hein?

A3: Assuntos que estão na vida de todos e o povo abafa o caso.

A2: Tu gosta, né?

A4: Oxe, eu também acho bom... todo mundo fala quando é assim.

Observamos, a partir dos depoimentos expostos, que entrevista contribuiu para conhecimento mais profundo acerca das experiências anteriores de nossos alunos em relação às suas concepções sobre a importância de aprender a língua espanhola e seus objetivos a partir desse aprendizado. Constatamos ainda, por meio dos questionamentos realizados aos participantes da pesquisa, seus interesses em relação ao curso e aos temas que poderíamos trabalhar em sala de aula. Esse conhecimento foi de fundamental importância para que selecionássemos textos que contribuíssem para o desenvolvimento da criticidade e argumentação dos alunos.

Demos prosseguimento à coleta e análise de dados a partir de um questionário sobre as justificativas que fundamentavam a escolha dos participantes da pesquisa pelo estudo do idioma espanhol. Esse questionário foi aplicado em uma das aulas realizadas em janeiro de 2016. Seguem alguns fragmentos de fala dos participantes da pesquisa: 
A1: Pra falar a verdade, eu nunca tive assim vontade de aprender uma língua estrangeira. Porém, quando eu entrei na UFAL no curso de Letras, "né"?... eu pra garantir a minha vaga logo no primeiro semestre e na primeira entrada, na primeira chamada. Eu optei pela licenciatura de Língua Espanhola, "né"? Com o intuito de entrar em Língua Portuguesa [...] depois eu fiquei sabendo que mesmo sendo de Língua Portuguesa eu teria que pagar Língua Espanhola por dois períodos. Então, foi quando eu comecei a estudar no CCC e, de repente, comecei a gostar pra valer de espanhol e eu não esperava isso, né? Pretendo estudar a Língua Espanhola para ter um segundo idioma.

A2: Desde pequena eu sempre me identifiquei muito com o idioma. E mesmo estudando no colégio... eu sempre busquei estudar por fora, porque além de querer o conhecimento de uma língua que eu amava tanto, eu sonhava em fazer um intercâmbio e também para futuras viagens e é isso.

A3: Ah, eu também... desde pequena eu assisto novela em espanhol e escutava música. E, agora, eu sigo na área de apicultura e eu recebo pelo e-mail muitos artigos em espanhol. Então, quanto mais informação a gente tiver, melhor.

A4: Eu já estudava inglês e como eu me formei em Gestão de Turismo, eu tenho interesse nessa área... trabalhar em agência. E viagens.

$\mathrm{Na}$ análise dos fragmentos, verificamos que os alunos estudavam a língua espanhola porque demonstravam interesse pelo idioma, no que diz respeito à leitura de artigos na área de estudos, às viagens, aos intercâmbios e ao emprego.

As atividades preferidas mencionadas pelos participantes da pesquisa para serem trabalhadas em sala de aula foram: debates, atividades relacionadas à música, conversação, escrita e exibição de filmes, como pode ser comprovado nos fragmentos a seguir:

A1: Eu gostaria de debates sobre temas atuais, né? Corrupção, homofobia. Essas coisas que estão presentes no nosso dia-a-dia. E algumas coisas que eu prezo, é a gramática. Trabalhar com a oralidade e a escrita e só.

A2: Eu gostaria de cultura, eu acho interessante. Quem pensa em viajar gostaria de conhecer a cultura de cada um deles. Eu gostaria de aprender através da música. Porque é um meio agradável de agregar os conhecimentos... eu gosto muito de música e de cantar.

A3: Ah... trabalhar mais a conversação e escrita. Porque quanto mais a gente conversa, mais a gente fixa informação.

A4: Eu gosto das suas atividades... ver filmes, algumas histórias. O senhor disse que vai trazer textos e isso vai ampliar o nosso vocabulário, e pode nos ajudar na pronúncia e na escrita. 
A partir das opiniões dos alunos foi possível perceber, ainda, uma preocupação em relação à oralidade e à escrita. E, para o desenvolvimento dessas habilidades, os participantes da pesquisa sugeriram o trabalho com temas relacionados à cultura, por meio de músicas e filmes. Tais argumentos justificam a realização dessa pesquisa, já que os estudantes demonstram interesse pela comunicação e escrita a partir de temas atuais, culturais e históricos, o que, de certa forma, relacionamos com as práticas de letramento crítico e desenvolvimento da argumentação.

Acreditamos que a aprendizagem de línguas deve ser vista como um processo de interação social (BAKHTIN, 2009), pois a língua é uma prática social constituída por sujeitos sócio-históricos. Ainda de acordo com a concepção bakhtiniana, a língua é diacrônica (em oposição a Saussure, que afirma que esta é sincrônica), isto é, ela muda com o passar do tempo. Assim, faz-se necessário o trabalho com a língua em funcionamento, levando em consideração que o aluno não deve apenas entender as regras gramaticais que regem o idioma estudado, mas também sobre seus processos retóricos, como defende Meniconi (2015):

é preciso ir além da análise do produto textual, isto é, o texto pronto, e passar a compreender e a trabalhar com a escrita dentro de uma perspectiva processual. Esse trabalho poderá levar à compreensão das dificuldades que os alunos possuem em relação à organização das ideias e adequação de seus objetivos retóricos. $O$ conhecimento destas dificuldades é de fundamental importância para a criação de estratégias didáticas que visem superá-las (MENICONI, 2015, p. 38).

Conforme salienta A1: "Minha experiência foi boa. Mas, eu preciso aprender a falar, sabe?”. Na afirmação de $\mathrm{A} 1$, podemos comprovar sua consciência em relação às dificuldades que ainda possui em relação à comunicação oral. A exposição dessa preocupação por parte da aluna contribuiu para que pensemos em estratégias didáticas que contribuíssem para o desenvolvimento dessa habilidade, a partir dos textos propostos para discussão oral e produção escrita argumentativa.

Em uma de nossas aulas, falamos sobre o tema homossexualidade. Para aprofundar sobre o assunto escolhido, levamos à sala de aula diferentes textos. A discussão sobre o tema se estendeu até o nosso Whatsapp, conforme pode ser comprovado no fragmento de fala de A1:

A1: Tem tantas crianças no mundo sem pai nem mãe, não tem pra que não deixar que os gays adotem, né? Será uma família que ama do mesmo jeito. Sendo sincera, eu antes não pensava assim... eu achava que não era 
certo isso. Mas, vai além de questão de você ser gay ou não, o amor é maior que isso.

No discurso da aluna percebemos que é possível conceber determinada situação de maneira diferente. Sua fala nos revela a possibilidade de (re)significarmos as nossas concepções e de refletirmos sobre por que pensamos de certa maneira, conforme aludem Jordão e Fogaça (2007):

Quando a língua é definida como discurso, o ensino de LEs se torna o ensino de novas formas de nos compreendermos e de percebermos o mundo. A língua como discurso implica o entendimento de nossas práticas de linguagem como práticas de (re)significarmos o mundo e o que acontece em nossa volta, a forma como percebemos a realidade (JORDÃO; FOGAÇA, 2007, p. 87).

O discurso de A1 revela a mudança em sua forma de perceber a realidade. Assim, consideramos que as aulas, sob a perspectiva do Letramento Crítico, podem "romper paradigmas e expandir perspectivas, ou seja, permitir a reconstrução do conhecimento local-global, do conhecimento relacional (mas não do relativismo) e da reflexão crítica sobre questões como heterogeneidade, diversidade, saberes, inclusão/exclusão, metodologias, novos materiais, novas mídias e tecnologias, novas epistemologias e crítica" (MONTE-MÓR; MENEZES DE SOUZA, 2009, p. 89). Em outras palavras, as práticas de letramento crítico nos ajudam a dispor dos recursos para que o aluno possa repensar o seu entendimento acerca de determinado assunto.

Em outro momento das aulas, escolhemos trabalhar com o tema referente ao aborto e suas implicações. Para tanto, levamos um infográfico sobre o aborto no México e um texto intitulado "No quiero tener hijos". Após a leitura do texto, realizamos uma discussão que provocou o seguinte questionamento:

Professor: Por que metade das mulheres casadas do México aborta?

A2.: Eu acho que é para poder trabalhar mesmo, porque sei lá...50\% são estudantes como nós. Isso não é uma questão de religião ou não. É uma questão de se sentir bem com o seu futuro. A mulher que aborta não é uma safada não, minha gente. Existem vários motivos para isso, olhem aí na imagem. Na minha opinião, em casos de estupro podia liberar.

O discurso da aluna A2 chama a atenção para o fato de que qualquer mulher poderia passar pela experiência do aborto independentemente do motivo. A aluna trouxe a realidade do outro para a sua própria realidade e se assumiu com um ser crítico, reflexivo e transformador. Nesse âmbito de análise, acreditamos que o letramento crítico se apresenta 
como uma perspectiva educacional que concebe a língua como formadora de ideias e valores, além de permitir ao sujeito reconhecer-se como autor e modificador de suas próprias crenças e valores.

O trabalho com as práticas letradas e argumentação foi prosseguido com a proposta de discussão e produção textual sobre o tema da amizade. Utilizamos o texto "Amistad entre mujeres", de Meniconi (2016). Escolhemos trabalhar com esse material devido ao fato de ter sido elaborado sob a perspectiva das estratégias retóricas (exemplos, questionamentos, afirmações, argumentos de autoridade, entre outros), para o desenvolvimento de uma pesquisa sobre a percepção feminina e masculina em relação à temática abordada (MENICONI, 2016, p. 87). No trabalho desenvolvido, percebemos que nossos alunos ficaram impactados com a leitura do texto proposto, já que este apresentava questionamentos que iam de encontro com o sentimento de fidelidade presente na amizade entre mulheres. Como parte das atividades sugeridas, pedimos que, usando as estratégias de argumentação trabalhadas em sala de aula, as alunas produzissem um texto sobre uma das temáticas discutidas. A seguir apresentamos um exemplo de produção textual realizado por uma das alunas participantes da pesquisa.

\section{HOMOSEXUALIDAD \\ Es lamentable que tantas personas sufran por su sexualidad. Es por eso que muchos no se revelan gais bul lesbianas por miedo se sienten solos, rechazados por la sociedad con prejuicios. También ocultar estos sentimentos por temor a ser de marginados, y al final sufren por tal opción. \\ Es necesario revisar tales ideales y respetar Los derechos de todos Los ciudadanos. \\ La lucha de homosexuales es enorme para revertir esta situación. Ellos buscan por respeto pero también, están sujetos de discriminación y víctimas de uma sociedad com prejuicios, que opera con prejuicio para tratar por igual aquellos considerado diferentes.}

Figura 1: texto 1 - Aluna A3.

Ao analisarmos o texto, percebemos que este se encontrava adequado em relação ao contexto, à situação comunicativa, ao destinatário e ao gênero do discurso. No entanto, observamos que alguns ajustes precisariam ser realizados em relação à defesa dos argumentos expostos. Como por exemplo, há um fragmento em que a aluna defende que 
os homossexuais buscam o respeito e estão sujeitos a discriminação. Essa ideia poderia ser comprovada, por exemplo, a partir de algum dado publicado em jornais ou revistas.

Em relação à gramática, percebemos alguns erros relacionados ao uso de artigos e em relação à ortografia: uso de "do" (em espanhol seria del), directo (seria derecho), a liberdad (a la libertad), lós (seria los). Como medida interventiva, além das correções de ordem gramatical e léxica, propusemos reestruturações em relação à forma de introduzir, desenvolver e concluir os fragmentos do texto. No campo da retórica e argumentação, solicitamos que a aluna apresentasse mais dados para respaldar as ideias defendidas. A seguir, apresentamos o texto reescrito, após as correções realizadas.

\footnotetext{
"Algunos países, presentan un índice muy alto de la violencia... Hay que destacar que el Brasil está en primera posición mundial en asesinatos homofóbicos, concentrando $44 \%$ del total de las muertes en todo el planeta, cerca de 770, según el Informe de los Asesinatos del LGBT de 2012." "Según Luiz Mott, antropólogo en la Universidad Federal de la Bahia, los datos son construidos a partir de los periódicos e informaciones de las organizaciones LGBT" (Texto reescrito pela aluna A3).
}

No texto reescrito, observamos que a aluna desenvolveu melhor os argumentos defendidos. A atividade de correção levou-a a fundamentar melhor suas ideias a partir do uso de dados e reestruturação dos fragmentos, tal como pode ser comprovado no fragmento: “...concentrando $44 \%$ del total de las muertes en todo el planeta, cerca de 770 , según el Informe de los Asesinatos del LGBT de 2012...”.

Por fim, concluímos o trabalho a partir da atividade de entrevista realizada com os alunos participantes da pesquisa, acerca da proposta de práticas letradas trabalhadas em sala de aula.

PROFESSOR: Em que as aulas sob a perspectiva do LC te fizeram melhorar?

A1.: Ah, eu aprendi a falar mais. A pensar de maneira diferente sobre alguns assuntos.

A3.: Eu também, aquele texto das mulheres me fez refletir. Já aconteceu comigo o que tá ali. 
A4.: Eita... e foi? Eu aprendi a ser mais aberta em relação ao aborto. Antes eu pensava que a mulher tinha que ter o filho e pronto. Mas, tem muita coisa envolvida aí.

A5.: Eu abri meus olhos pra muita coisa.

A partir do discurso destas alunas é possível compreender os reflexos do trabalho sob as perspectivas do letramento crítico: elas não aprenderam apenas os aspectos gramaticais do idioma. Mas, descobriram como refletir acerca de suas práticas enquanto seres humanos e a respeitar; ao mesmo tempo, contemplar a opinião do outro percebendo que esta também é válida. Ainda é possível perceber que estas aprenderam sobre os outros e sobre elas mesmas.

\section{Considerações Finais}

A pesquisa desenvolvida nos levou à percepção de que pesquisar as teorias do letramento crítico e da argumentação e aplicá-las em sala de aula constitui-se como uma proposta desafiadora e, ao mesmo tempo, significativa tanto para os alunos quanto para os professores.

Antes de conhecer a perspectiva do letramento crítico, a gramática direcionava a maior parte das atividades desenvolvidas no processo de ensino-aprendizagem da língua espanhola, o que tornava nossas aulas monótonas e desinteressantes para os alunos. As práticas de letramento crítico, desenvolvidas a partir dessa pesquisa, no entanto, modificaram a dinâmica de nossas aulas. Percebemos que as propostas de leitura de textos argumentativos, discussão e produção textual tornaram nossas aulas mais interativas, proveitosas e significativas para os participantes da pesquisa (alunos e professores/pesquisadores).

Os alunos aprenderam a refletir sobre temas diversos abordados no idioma espanhol e, em muitas situações, reelaboraram suas ideias, opiniões e concepções previamente construídas.

Além de encontrar um novo lugar para o ensino da gramática (a partir do texto e para o texto), passamos também a considerar os alunos o foco de nossas atenções. "Saímos 
de cena" e passamos a valorizar mais a participação e expressão do ponto de vista dos discentes.

Observamos ainda que trabalho a partir de temas polêmicos desenvolvidos nessa pesquisa levou os alunos a se perceberem como sujeitos e a (re)significar sua visão de mundo e suas práticas sociais. Além do mais, os resultados da pesquisa revelaram uma melhora significativa na produção escrita dos alunos. Eles aprenderam a utilizar as técnicas argumentativas para defender suas ideias e, ao mesmo tempo, planejar, redigir e revisar seu texto.

Por fim, ressaltamos, uma vez mais, a importância desta pesquisa para o nosso trabalho docente. Ela nos possibilitou a reflexão e mudança de nossa prática. Ao invés de centrar nossas aulas no ensino das estruturas gramaticais, aprendemos a trabalhar com o texto e valorizar mais a participação de nossos alunos. Além do mais, as teorias de letramento crítico nos ajudaram a considerar o conhecimento de mundo e experiências dos alunos, bem como o desenvolvimento da reflexão e da criticidade.

\section{Referências}

ARISTÓTELES. Retórica. Trad. Manuel Alexandre Júnior, Paulo Farmhouse Alberto e Abel do Nascimento Pena. Lisboa: Imprensa Nacional; Casa da Moeda, 1998.

BAKHTIN, M.; VOLOCHINOV, V. N. Marxismo e filosofia da linguagem: problemas fundamentais do método sociológico na ciência da linguagem. 13 ed. Trad. M. Lahud e Y. F. Vieira. São Paulo: Hucitec, 2009.

BARTON, D.; HAMILTON, M. Literacy practices. In: BARTON, D.; HAMILTON, M.; IVANIC, R. (Org.). Situated literacies: reading and writing in context. Londres:

Routledge, 2000, p. 7-15.

FLOWER, L.; HAYES, J. R. A cognitive process theory of writing. College composition and communication v. 32, $\mathrm{n}^{\circ} 4,1981$. Disponível em:

< https://pdfs.semanticscholar.org/1b87/33d4ead43f5298891eb38608747ace09dfc6.pdf>. Acesso em: 2 jul. 2018.

FREIRE, P. Cartas à Guiné-Bissau: registros de uma experiência em processo. Rio de Janeiro: Paz e Terra, 1977.

GEE, J. P. The new literacy studies: from "socially situated" to the work of the social. In: BARTON, D.; HAMILTON, M.; IVANIC, R. (Org.). Situated literacies: reading and writing in context. Londres: Routledge, 2000, p. 180-196. 
HABERMAS, Jürgen. Conciencia moral y comunicativa. Editorial Península, 1991.

JORDÃO, C.; FOGAÇA, F. C. Ensino de inglês, letramento e cidadania: um triângulo amoroso bem-sucedido. Línguas e Letras v. 8, n 14, 2007, p. 79-105.

KOCH, I. A argumentação pela linguagem. São Paulo: Cortez, 2002.

MENICONI, F. C. O ensino da produção escrita para alunos iniciantes no aprendizado da língua espanhola: uma pesquisa-ação no curso de letras. Tese (Doutorado em Letras e Linguística). Maceió: Universidade Federal de Alagoas, 2015.

MENICONI, F. C; SILVEIRA, M. I. M. Diferenças de sentido e percepções da leitura de um texto argumentativo: efeito da retórica nos discursos feminino e masculino. In: JUNIOR, J. N. B. M.; SANTOS, M. F. (Org.). Perspectivas em retórica e análise da conversação: um percurso em gêneros textuais/discursivos. Maceió: Edufal, 2016, p. 87107.

MENICONI, F. C. Escrita em língua espanhola: é possível produzir textos nas fases iniciais do ensino-aprendizagem de um novo idioma? Maceió: Edufal; Imprensa Oficial Graciliano Ramos, 2017.

MÉSZÁROS, I. Para além do capital: rumo a uma teoria da transição. São Paulo: Boitempo, 2002.

MEYER, M. A retórica. São Paulo: Ática, 2007.

MONTEMÓR, W.; MENEZES DE SOUZA, L. M. T. Formação de professores nas teorias dos novos letramentos e multiletramentos: o ensino crítico de línguas estrangeiras na escola. São Paulo: USP, 2009.

PERELMAN, C.; OLBRECHTS-TYTECA, L. Tratado da argumentação: a nova retórica. Trad. Maria Ermantina de Almeida Prado Galvão. São Paulo: Martins Fontes, 2005.

REBOUL, O. Introdução à retórica. São Paulo: Martins Fontes, 1998.

ROCHA, R. B. O ensino da escrita argumentativa na perspectiva dialógica. São Paulo: Bakhtiniana, 2012, p. 199-218.

ROJO, R. Letramento e capacidade de leitura para a cidadania. São Paulo: SEE; CENP, 2004.

SOSA, B. N. La producción e interpretación de la argumentación como experiencia retórica. Revista de la Facultad v. 11, 2011, p. 175-192.

SANTOS, R.; IFA, S. O letramento crítico e o ensino de inglês: reflexões sobre a prática do professor em formação continuada. The ESPecialist v. 34, nº 1, 2013, p. 1-23.

SOARES, M. Letramento: um tema em três gêneros. Belo Horizonte: Autêntica, 1998.

THIOLLENT, Michel. Pesquisa-ação nas organizações. São Paulo: Atlas, 1997. 


\section{Abstract}

This article is the result of a research about the process of critical formation and argumentative writing in Spanish Language. It's based on the contributions of Barton; Hamilton (2000) and Gee (2000), who defend the valorization of the subject; Rojo (2004), who discuss about considering the social context during the learning process, Perelman; Olbrechts-Tyteca (2005), who discuss argumentative aspects of the language and Meniconi (2017), who defend the teaching of writing in Spanish Language in the initial stages of their learning. It's a qualitative research which is ready to analyze the teaching-learning's process in argumentative writing in Spanish. The results revealed that students are able to produce argumentative texts in the language studied. The developed didactic sequence made it possible to develop criticality in the texts produced, as well as the use of argumentative strategies to defend the point of view and values in Spanish.

Keywords: Literacy. Argumentative Writing. Teachinglearning Spanish Language

Recebido em: 05/02/2018.

Aceito em: 03/06/2018. 